\title{
ANÁLISE DE TRILHA PARA CRESCIMENTO E RENDIMENTO DE GENÓTIPOS DE MILHO SOB DIFERENTES DOSES NITROGENADAS
}

\section{PATH ANALYSIS FOR GROWTH AND GRAIN YIELD OF CORN GENOTYPES UNDER DIFFERENT NITROGEN DOSES}

\author{
Lucas Alves de FARIA ${ }^{[1 ; *]}$, Joenes Mucci PELÚZIO ${ }^{[1]}$, Flávio Sérgio AFFÉRRI ${ }^{[2]}$, Edmar Vinicius de CARVALHO ${ }^{[1]}$, \\ Michel Antônio DOTTO ${ }^{[1]}$ e Eduardo Alves de FARIA ${ }^{[1]}$

\begin{abstract}
[1] Universidade Federal do Tocantins (UFT), Curso de Agronomia, Campus Gurupi. Rua Badejós, Chacaras 69/72, Lt 07, Zona rural. 77402-970. GurupiTO, Brasil. joenesp@mail.uft.edu.br; ed.vinicius_carvalho@hotmail.com; micheldotto@hotmail.com; eduardoalves_16@hotmail.com.

[2] Universidade Federal de São Carlos (UFSCar), Centro de ciências naturais. Fazenda Lagoa do Sino Aracaçu CEP 18.295-990, Buri-SP, Brasil.
\end{abstract} \\ flavioafferri@gmail.com
}

*Autor para correspondência: lucasfaria_16@hotmail.com

\begin{tabular}{|c|c|}
\hline INF. ARTIGO & RESUMO \\
\hline Recebido: 10/27/2014 & $\begin{array}{l}\text { A análise de trilha permite o desdobramento do coeficiente de correlação em efeitos } \\
\text { diretos e indiretos, permitindo o estudo de causa e efeito de uma característica sobre }\end{array}$ \\
\hline Aceito: 03/08/2015 & a outra. Como o nitrogênio influência no desenvolvimento da cultura, também pode \\
\hline Publicado em: 03/24/2015 & influenciar nos resultados da análise de trilha. O objetivo desse trabalho foi avaliar a \\
\hline Document Object Identifier & reprodutivo (R1), o rendimento de grãos de doze genótipos de milho sob três doses \\
\hline 10.18067/jbfs.v2i1.13 & diferentes de nitrogênio em cobertura, e a contribuição dessas características no \\
\hline Editor: V. H. G. Sales & representados por três doses de nitrogênio em cobertura, 20,80 e $140 \mathrm{~kg} \cdot \mathrm{ha}^{-1}$. O \\
\hline jbfs@ifap.edu.br & $\begin{array}{l}\text { delineamento foi em blocos ao acaso com doze tratamentos e três repetições. Pela } \\
\text { análise de trilha, verificou-se que a altura de plantas } 4 \text { (AP4) e taxa de crescimento } 3\end{array}$ \\
\hline ID JBFS0132014 & $\begin{array}{l}\text { (TX3) foram os componentes de rendimento que apresentaram maior correlação total } \\
\text { com a produtividade }(0,462 \text { e } 0,661 \text {; respectivamente), quando utilizado a dose } 20 \mathrm{~kg}\end{array}$ \\
\hline Avaliação às cegas por pares & N.ha-1. O genótipo G3 foi o que apresentou melhores resultados, e o nitrogênio \\
\hline $\begin{array}{l}\text { Prot. } 0132014 R 01 \\
\text { Prot. } 0132014 R 02\end{array}$ & $\begin{array}{l}\text { influenciou de forma significativa as características altura de planta e produção de } \\
\text { grãos, com maior eficiência para a dose } 80 \text {. }\end{array}$ \\
\hline
\end{tabular}

Copyright: @ 2015 JBFS all rights (BY NC SA)

Palavras-chave: Altura, incremento, estados fenológicos, Zea mays, Tocantins.

ABSTACT - Path analysis allows the deployment of the correlation coefficient in direct and indirect effects, allowing the study of cause and effect of a characteristic over the other. As nitrogen influences the development of culture, can also influence the path analysis results. The aim of this work was to evaluate the plant height and their daily increment the vegetative stage (V6) until the reproductive stage (R1), and grain yield of twelve genotypes under three different levels of nitrogen in coverage, and the contribution of these characteristics on grain yield. Three experiments were conducted, and each one was represented by three levels of nitrogen in coverage, 20, 80 e $140 \mathrm{~kg} \cdot \mathrm{ha}^{-1}$. The experimental design was randomized blocks with twelve treatments and three replications. For the Path analysis, plant height 4 (AP4) and growth rate 3 (TX3) were the yield components that showed the highest total correlation with the yield ( 0.462 and 0.661 ; respectively), when it was used $20 \mathrm{~kg}$ N.ha-1. The G3 genotype had shown the best results, and the nitrogen significantly influenced the characteristics: plant height and grain yield with greater efficiency for the level 80 of nitrogen in covered.

Keywords: Height, Increment, Phenological states, Zea mays, Tocantins

Financiamento: Os autores reportam que houve suporte ou auxílio financeiro para a realização da pesquisa pelo CNPQ (Conselho Nacional de Desenvolvimento Científico e Tecnológico.

Conflito de interesse: Os autores declaram que não há conflito de interesse.

Como referenciar esse documento (ABNT):

FARIA, L.A.; PELUZIO, J.M.; AFFÉRRI, F.S.; CARVALHO, E.V.; DOTTO, M.A.; FARIA, E.A. Análise de trilha para o crescimento e rendimento de genótipos de milho sob diferentes doses nitrogenadas. Journal of Bioenergy and Food Science, Macapá, v.2, n.1, p.1-11, jan./mar., 2015. DOI: $10.18067 / j b f s . v 2 i 1.13$ 
INTRODUÇÃO

Nos últimos anos a cultura do milho tem se destacado como uma das mais importantes no cenário agrícola mundial, isso tem ocorrido devido a sua grande utilização como integrante básico e indispensável na alimentação humana e animal, pois é uma excelente fonte proteica e energética, e também pela sua ampla utilização como matériaprima para indústria na fabricação de diversos tipos de produtos alimentícios ou não (CIB, 2006).

O Brasil é o terceiro maior produtor mundial deste cereal, sendo que cerca de 16 milhões de hectares são colhidos a cada safra, destacando-se que no ano agrícola 2012/2013 foram colhidas aproximadamente 81,5 milhões de toneladas. No Tocantins, a área destinada para o plantio é de 95,2 mil ha, produtividade média de $4.700 \mathrm{~kg} \cdot \mathrm{ha}^{-1}$ (CONAB, 2013; IBGE, 2013).

Tem se observado grandes avanços em relação ao cultivo e desenvolvimento desse cereal, e valores significantes de incrementos na produção de grãos, sendo essa uma das culturas que mais se tem observado tal aumento. Fato esse que ocorre principalmente em consequência de melhorias na genética, originando novos materiais de milho (SINCLAIR, 1998).

A produtividade de grãos de genótipos de milho possui uma relação com a taxa de crescimento da cultura, e com o número de grãos produzidos, porém poucos trabalhos existem sobre essa informação. Alguns pesquisadores relatam a influência de fotoassimilados no crescimento do grão, porém sendo de pouca influência quando o processo de determinação do número de grãos por espiga já se encontrar ocorrido (MAGALHÃES \& JONES, 1990).

O rendimento de grãos é dependente da absorção de assimilados, e que a fonte desses assimilados é quem determina o potencial produtivo (TOLLENAAR, 1991; TOLLENAAR \& WU, 1999), enquanto outros acreditam que 0 potencial produtivo do material está relacionado com a sua capacidade de armazenamento de assimilados pelo grão (MAGALHÃES \& JONES, 1990). Assim a maior eficiência na absorção da radiação e no uso dessa radiação interceptada, condições de temperaturas ideais para o desenvolvimento da cultura, e o estado fisiológico em que a cultura se encontra nesse período, são fatores que determinam a taxa de crescimento da planta e seu potencial produtivo (ANDRADE et al., 1993a; ANDRADE et al., 1993b; OTEGUI \& BONHOMME, 1998).
Algumas características que antecedem o estágio reprodutivo da planta, tais como: altura de planta, taxa de crescimento, índice de área foliar, entre outras, podem apresentar associação com a produtividade de grãos (FARIA et al., 2014). A altura de plantas também pode apresentar correlação positiva com a massa seca da planta (ALMEIDA et al., 2003; PAZIANI et al., 2009). Segundo Araus et al., (2014) o emprego de técnicas mais simples para avaliação em campo, tem contribuído positivamente, facilitando o trabalho de coleta de dados e influenciando na obtenção de bons resultados.

A análise de correlação indica apenas a presença ou não de uma associação, seja essa positiva ou negativa, entre duas características, a intensidade e a relação linear ou não linear entre elas (CHARNET et al., 2008). Porém o estudo da correlação entre as características não possibilita formular conclusões sobre as causas e efeitos dessas relações, o que impossibilita o conhecimento de qual tipo de associação existe entre os caracteres analisados (KUREK et al., 2001; GONÇALVES et al., 2003).

A análise de trilha, proposta por Wright (1921), permite a desintegração ou partição do coeficiente de correlação entre os efeitos diretos e indiretos (coeficiente de trilha). Além disso, essa análise permite de maneira mais fácil, a seleção de plantas por meio do efeito indireto de outros caracteres que interferem positivamente sobre a produtividade (COIMBRA et al., 2004; NOGUEIRA et al., 2013).

Este trabalho teve por objetivo avaliar a altura de plantas, seu incremento diário do estágio vegetativo até o estágio reprodutivo, e o rendimento de grãos de doze genótipos de milho sob três doses diferentes de nitrogênio em cobertura, e a contribuição dessas características no rendimento de grãos.

\section{MATERIAL E MÉTODOS}

Na safra 2012/13 foram conduzidos três experimentos de campo, no município de Gurupi-TO (11ㄴㄱ'45"S; 4904'07'W; 280 m de altitude), em Latossolo Vermelho Amarelo, com clima do tipo B1wA'a' úmido com moderada deficiência hídrica, segundo a classificação de Köppen, com Precipitação de $828 \mathrm{~mm}$.

O resultado da análise de solo na camada de 0-20 cm está na Tabela 1. 
Tabela 1. Análise química e de textura do solo, na camada $0-20 \mathrm{~cm}$.

Table 1. Chemical analysis and soil texture in the layer $0-20 \mathrm{~cm}$.

\begin{tabular}{|c|c|c|c|c|c|c|c|c|c|c|c|}
\hline \multicolumn{12}{|c|}{ Propriedades do solo } \\
\hline Unidades & & ppm & & (cmol. & & & (\%) & $\left(\mathrm{g} \cdot \mathrm{dm}^{-3}\right)$ & & (g.kg & \\
\hline \multirow{2}{*}{ Resultados } & $\begin{array}{c}\mathrm{pH} \\
\mathrm{CaCl}_{2}\end{array}$ & $P$ & $\mathrm{Ca}+\mathrm{Mg}$ & $\mathrm{H}+\mathrm{Al}$ & K & CTC & V & MO & Argila & Silte & Areia \\
\hline & 5,4 & 6,4 & 3,3 & 1,7 & 0,11 & 5,12 & 66,86 & 23 & 340 & 90 & 570 \\
\hline
\end{tabular}

Foram realizados três experimentos, com plantio realizado em 11 de dezembro de 2013 ambos sobre sistema convencional, os quais foram representados por três doses de nitrogênio em cobertura, $20 \mathrm{~N}, 80 \mathrm{~N}$ e $140 \mathrm{~N}$ (kg.ha-1), denominados, respectivamente, como baixo, médio e alto $\mathrm{N}$, e aplicadas em dose única quando as plantas estavam no estágio de seis folhas expandidas (V6). Foram utilizados 12 genótipos de milho, sendo seis populações de polinização aberta (P1, P2, P3, P4, P5 e P6), desenvolvidas por top cross de linhagens com testador de base genética ampla, e seis genótipos comerciais (G1 - AL Bandeirantes; G2 - BRS Gorutuba; G3 - AL Piratininga; G4 - BR 205; G5 - Órion e G6 - BRAS 3010), utilizados comercialmente na região por produtores rurais.

Nestes experimentos, foi utilizado o delineamento em blocos casualizados com doze tratamentos e três repetições, a parcela experimental foi composta por duas linhas de cinco metros, com espaçamento de $0,75 \mathrm{~m}$ entre linhas. 0 número de plantas, após o desbaste, foi de 50.000 plantas por hectare.

$A$ adubação de plantio foi realizada com a formulação N-P-K 52515 + 0,5\% de Zn, no sulco de plantio, na dose de 500 kg.ha-1, em todos os experimentos. Os demais tratos culturais foram efetuados assim que se fizeram necessários, seguindo as recomendações técnicas da cultura do milho de acordo com (FANCELLI \& DOURADO NETO, 2000).

A partir dos estágios V6-V8 (seis a oito folhas totalmente expandidas) foram iniciadas as avaliações semanais de altura de plantas (AP), que se estenderam até o estádio VT-R1 (florescimento masculino e feminino), totalizando quatro medições (1, 2, 3 e 4), em cm, sendo denominadas da seguinte forma: AP1- estágio V6-V8; AP2 - estágio V8-V10; AP3 - estágio V10-V12 e AP4 - estágio VT-R1. Em cada avaliação foi mensurada a altura de cinco plantas representativas por parcela.

No estágio R6 (maturação fisiológica) foi realizada a colheita das plantas representativas da parcela, onde foi avaliado o peso de grãos (PG), em g. planta $^{-1}$ corrigido a $13 \%$ de umidade. Ainda, foi estimada a Taxa de crescimento diário (TX) totalizando três medições $(1,2$ e 3$)$ em $\mathrm{cm}$, sendo denominadas da seguinte forma: TX1 - entre os estágios V6-V8 e V8-V10; TX2 - entre os estágios V8V10 e V10-V12 e TX3 - entre os estágios V10-12 e VTR1.

Após a tabulação dos dados, os mesmos foram submetidos aos testes de normalidade, e posteriormente as seguintes análises estatísticas:

i. Análise de variância conjunta (12 genótipos $x$ 3 experimentos).

ii. Teste de médias, Scott-Knott a $5 \%$ de significância, quando detectada diferenças significativas pela análise de variância supracitada.

iii. Análise de comparação de médias feita pelo teste $\mathrm{t}$.

iv. Análise de correlação entre as variáveis avaliadas, para cada condição de nitrogênio em cobertura ( $n=36$ ) e, análise de trilha considerando as avalições de altura de plantas ou as taxas de crescimento diário como variável dependente e o peso de grãos como variável independente.

As análises estatísticas foram realizadas por meio do software SISVAR ${ }^{\circledR}$ desenvolvido por Ferreira (2003) e GENES desenvolvido por Cruz (2001).

\section{RESULTADOS E DISCUSSÃO}

Pela análise de variância conjunta, observouse diferença significativa entre os genótipos em todas as características avaliadas, exceto para TX2, diferentemente do que foi encontrado por Soares et al., (2011), onde não se observou significância entre os genótipos e altura de plantas após o início do florescimento (R1). Também foi observada influência significativa das doses de nitrogênio para as características AP1, AP3, AP4 e PG, e a não significância da interação genótipo $\mathrm{x}$ doses de nitrogênio conforme descrito na (Tabela 2). Interação não significativa entre genótipos de milho e doses de nitrogênio para produção de grãos também foi encontrado por Szelés (2007), quando

$$
3 \text { | P á g i n a }
$$


utilizou 162 linhagens e duas doses de nitrogênio, em Sete Lagoas - MG.

A interação (relação entre duas ou mais características) é considerada um aspecto importante em um programa de melhoramento, pois ela interfere na recomendação de cultivares além de dificultar o trabalho do melhorista no processo de identificação de genótipos adaptados (superiores) em diferentes ambientes (RAMALHO et al. 1993).

Segundo Soares et al. (2011) a ausência dessa interação proporcionaria uma grande facilidade aos melhoristas, pois um material bom (alta produtividade, resistente a doença, etc.) precisaria de um simples ensaio para apresentar resultados universais, e se adaptaria facilmente em vários ambientes por mais distintos que fossem.

Tabela 2. Análise de variância com a decomposição dos quadrados médios da interação genótipos $x$ doses de nitrogênio em cobertura, de 12 genótipos de milho avaliados sob três doses de nitrogênio na safra 2012/2013, Gurupi- TO.

Table 2. Variance analysis with the decomposition of the mean squares in the interation, genotype $x$ nitrogen levels in coverage of 12 maize genotypes evaluated under three levels of nitrogen in the 2012/2013 harvest, Gurupi-TO.

\begin{tabular}{|c|c|c|c|c|c|}
\hline \multirow{2}{*}{ Características } & \multicolumn{3}{|c|}{ QM } & \multirow{2}{*}{$\mathrm{CV}$} & \multirow{2}{*}{ Média } \\
\hline & Genótipo (G) & Nitrogênio (N) & $\mathrm{G} * \mathrm{~N}$ & & \\
\hline AP1 & $157,54^{* *}$ & $122,33^{* *}$ & $12,37^{\mathrm{ns}}$ & 5,82 & 76,62 \\
\hline AP2 & $814,18^{*}$ & $325,95^{\mathrm{ns}}$ & $69,73^{\text {ns }}$ & 8,74 & 119,94 \\
\hline AP3 & $1179,26^{*}$ & $838,92^{*}$ & $181,50^{\text {ns }}$ & 9,23 & 175,38 \\
\hline AP4 & $649,75^{* *}$ & $1695,81^{* *}$ & $162,75^{\mathrm{ns}}$ & 5,71 & 218,59 \\
\hline TX1 & $0,26^{* *}$ & $0,14^{\mathrm{ns}}$ & $0,07^{\text {ns }}$ & 10,9 & 2,46 \\
\hline $\mathrm{TX} 2$ & $0,16^{\mathrm{ns}}$ & $0,33^{\text {ns }}$ & $0,12^{\text {ns }}$ & 13,1 & 2,79 \\
\hline TX3 & $0,86^{* *}$ & $0,30^{\text {ns }}$ & $0,21^{\text {ns }}$ & 21,6 & 2,42 \\
\hline PG & $657,46^{* *}$ & $1804,14^{* *}$ & $158,10^{\text {ns }}$ & 15,9 & 86,79 \\
\hline
\end{tabular}

$\mathrm{AP}^{1,2,3,4}$ : altura de planta $(\mathrm{cm})$ de acordo com data de avaliação semanal; $\mathrm{TX}^{1,2,3}$ : taxa de crescimento (cm/dia) de acordo com os intervalos de avaliação; PG: produção de grãos (g.planta $\left.{ }^{-1}\right){ }^{*}{ }^{* *}$ Significativo a $5 \%$ e $1 \%$ respectivamente; ns: não significativo pelo teste $\mathrm{F}$; CV: coeficiente de variação (\%).

$A P^{1,2,3,4}$ : plant height $(\mathrm{cm})$ according to date weekly evaluation; $T X^{1,2,3}:$ growth rate $(\mathrm{cm} /$ day) according to the evaluation interval; PG: grain yield (g.planta ${ }^{-1}$ ); *, ** Significant at $5 \%$ and $1 \%$ respectively; ns: not significant by F test; CV: coefficient of variation (\%).

É notório de que existem interações (Genótipo x Ambiente) positivas e que essas quando associadas às características previsíveis do ambiente, podem proporcionar produtividades mais elevadas, mostrando que a ocorrência de uma interação nem sempre é um fator negativo, pois em certas ocasiões se torna uma oportunidade de se obter bons resultados (DUARTE \& VENCOVSKY, 1999).

As diferenças significativas encontradas entre as doses de nitrogênio (Tabela 2) demonstraram que as quantidades de $\mathrm{N}$ aplicadas (20 N, $80 \mathrm{~N}$ e $140 \mathrm{~N}$ ) foram adequadas para diferenciar os ambientes para as características altura de planta (AP1, AP3 e $A P 4)$ e produtividade de grãos (PG), o que também foi encontrado por Soares et al. (2011) nos seus estudos com as doses $12 \mathrm{~N}$ e $120 \mathrm{~N}$, demonstrando a importância e a influência desse nutriente para as características avaliadas.

Na característica AP2 foi observado que não houve diferenças significativas em relação às doses de N (Tabela 2). Esse fato tende a ser explicado por possíveis alterações ambientais, tais como: temperaturas inadequadas (altas temperaturas) e/ou estresse hídrico (veranico) influenciando na absorção ou assimilação de $\mathrm{N}$, condições observadas nos dados climáticos que foram registrados pela estação experimental no município de Gurupi-TO durante a safra verão 2012/2013 (INMET, 2013).

A falta de água nessa fase (V8-V10) pode resultar em uma menor produção de carboidratos, mostrando que também existe uma relação entre o estresse hídrico e a fotossíntese, onde a falta de água disponibiliza uma menor quantidade de $\mathrm{CO}_{2}$ para a fotossíntese, interferindo no processo de elongação celular, provocando a diminuição da capacidade de armazenagem de açúcares no colmo, resultando em colmos mais finos, plantas de menor porte e área foliar (MAGALHÃES et al., 2002).

O genótipo $G 2$ foi o único entre todos avaliados, que se enquadrou no grupo de média superior para todas as avaliações de altura de planta (Tabela 3). 
Tabela 3. Médias de alturas de plantas (AP) em $\mathrm{cm}$ dos estágios V6-V8 até o estádio VT-R1 de 12 genótipos de milho avaliados sob três doses de nitrogênio na safra 2012/2013, Gurupi- TO.

Table 3. Averages plant heights (AP) $\mathrm{cm}$ in the V6-V8 stages to the VT-R1 stage of 12 maize genotypes evaluated under three levels of nitrogen in the 2012/2013 harvest, Gurupi- TO.

\begin{tabular}{ccccccccc}
\hline Genótipo & AP1 & & AP2 & & AP3 & AP4 \\
\hline P1 & 73,85 & B & 112,70 & C & 169,63 & B & 203,11 & B \\
P2 & 77,74 & A & 118,85 & C & 172,70 & B & 217,63 & A \\
P3 & 75,96 & B & 124,33 & B & 173,04 & B & 215,15 & B \\
P4 & 75,04 & B & 117,67 & C & 183,04 & A & 224,07 & A \\
P5 & 81,37 & A & 128,37 & B & 187,00 & A & 225,85 & A \\
G1 & 71,26 & C & 108,56 & D & 164,11 & B & 212,78 & B \\
G2 & 82,78 & A & 141,00 & A & 197,41 & A & 217,93 & A \\
G3 & 77,63 & A & 117,93 & C & 180,74 & A & 228,11 & A \\
G4 & 68,81 & C & 104,63 & D & 153,67 & B & 203,89 & B \\
G5 & 80,19 & A & 123,96 & B & 178,33 & A & 225,52 & A \\
P6 & 74,59 & B & 117,67 & C & 166,81 & B & 224,26 & A \\
G6 & 80,19 & A & 123,56 & B & 178,11 & A & 224,74 & A \\
\hline
\end{tabular}

Médias com a mesma letra na coluna não diferem estatisticamente pelo teste Scott-Knott a $5 \%$ de significância.

Averages with the same letter in the column do not differ statistically by Scott-Knott test at $5 \%$ significance.

Para TX1 apenas o genótipo G2 foi classificado no grupo de média superior, porém esse mesmo genótipo se classificou no menor grupo de média em TX3 enquanto outros dez genótipos (P2, P3, P4, P5, $\mathrm{G1}, \mathrm{G} 3, \mathrm{G} 4, \mathrm{G} 5, \mathrm{P} 6$ e G6) se classificaram no grupo de média superior, mostrando que esses materiais mesmo possuindo alturas diferentes, tiveram um incremento diário semelhante nesse período
(Tabela 4). Já para produção de grãos quatro genótipos (P2, G3, G5 e G6) obtiveram médias superiores (Tabela 4), sendo que esses mesmos genótipos de acordo com a Tabela 3, obtiveram médias superiores para AP4, mostrando uma associação positiva entre altura de planta e produção de grãos, como também foi encontrado por Faria et al. (2014).

Tabela 4. Médias de taxas de crescimento (TX) em $\mathrm{cm} /$ dia, dos intervalos a partir dos estágios V6-V8, até o estádio VT-R1 e Produção de grãos (PG em g.planta ${ }^{-1}$ ), de 12 genótipos de milho avaliados sob três doses de nitrogênio na safra 2013/2014, Gurupi- TO.

Table 4. Averages growth rate (TX) in cm / day, in the V6-V8 stages to the stage VT$R 1$ and grain production (in g.planta PG-1) of 12 maize genotypes evaluated under three doses of nitrogen in the crop 2013/2014, Gurupi- TO, Brazil.

\begin{tabular}{ccccccc}
\hline Genótipo & TX1 & \multicolumn{2}{c}{ TX3 } & PG \\
\hline P1 & 5,55 & C & 4,78 & B & 83,21 & B \\
P2 & 5,87 & C & 6,42 & A & 96,28 & A \\
P3 & 6,91 & B & 6,02 & A & 79,64 & B \\
P4 & 6,09 & C & 5,86 & A & 78,87 & B \\
P5 & 6,71 & B & 5,55 & A & 88,20 & B \\
G1 & 5,33 & C & 6,95 & A & 85,66 & B \\
G2 & 8,32 & A & 2,93 & B & 73,60 & B \\
G3 & 5,76 & B & 6,77 & A & 98,40 & A \\
G4 & 5,12 & B & 7,17 & A & 78,20 & B \\
G5 & 6,25 & B & 6,74 & A & 99,34 & A \\
P6 & 6,15 & B & 8,21 & A & 86,65 & B \\
G6 & 6,20 & B & 6,66 & A & 93,38 & A \\
\hline
\end{tabular}

Médias com a mesma letra na coluna não diferem estatisticamente pelo teste Scott-Knott a 5\% de significância.

Averages with the same letter in the column do not differ statistically by Scott-Knott test at $5 \%$ significance. 
De acordo com a Tabela 5 na dose $140 \mathrm{~N}$ os genótipos apresentaram os menores valores de médias em todas as avaliações de AP. Na AP1 com a dose $20 \mathrm{~N}$ os genótipos apresentaram a maior média entre as demais, isso pode ser explicado pelo fato dessa primeira avaliação ter sido realizada próximo da adubação de cobertura, onde a presença de $\mathrm{N}$ no solo juntamente com a menor dose (20 N) foi capaz de atender a necessidade da planta no estágio avaliado (Tabela 5), diferente do que foi observado em AP3, onde a dose de $\mathrm{N}$ em que proporcionou maior média foi $80 \mathrm{~N}$, podendo ser explicado pelo possível aumento na extração de $\mathrm{N}$ do solo nesse estádio e pela dose $20 \mathrm{~N}$ ser baixa e disponibilizar uma quantidade não suficiente para a necessidade da cultura e a dose $140 \mathrm{~N}$ por ser excessiva ao que a cultura requer nesse estádio (Tabela 5).

Tabela 5. Médias de altura de plantas (AP) em $\mathrm{cm}$, a partir dos estágios $\mathrm{V} 6-\mathrm{V} 8$, até o estádio VT-R1, e produção de grãos (PG em g.planta-1 ${ }^{-1}$ ), de12 genótipos de milho avaliados sob três doses de nitrogênio na safra 2012/2013, Gurupi- TO.

Table 5. Averages Plant height (AP) in $\mathrm{cm}$, in the V6-V8 stages to the VT-R1 stage, and grain yield (PG g.planta in-1), of 12 maize genotypes evaluated under three doses of nitrogen in the crop 2013/2014, Gurupi- TO, Brazil.

\begin{tabular}{|c|c|c|c|c|c|c|c|c|}
\hline Nitrogênio & AP1 & & AP3 & & AP4 & & PG & \\
\hline 20 & 78,49 & A & 172,76 & B & 212,27 & B & 78,85 & B \\
\hline 80 & 76,56 & B & 180,95 & A & 225,89 & A & 89,06 & A \\
\hline 140 & 74,81 & B & 172,44 & B & 217,60 & B & 92,45 & $A$ \\
\hline
\end{tabular}

$*, * *$ Significativo à $5 \%$ e $1 \%$ respectivamente pelo teste $\mathrm{t}$.

*, ** Significant at the $5 \%$ and $1 \%$ respectively by t test.

$\mathrm{Na}$ AP4 a dose de $\mathrm{N}$ em que foi obtida a maior média também foi a dose $80 \mathrm{~N}$, indicando o mesmo ocorrido para AP3 (Tabela 5). Para PG se observou que as doses $80 \mathrm{~N}$ e $140 \mathrm{~N}$ proporcionaram valores superiores, mostrando que apesar de não apresentar as maiores médias em AP1, AP3 e AP4, a dose $140 \mathrm{~N}$ contribui para a maior produção de grãos, porém não se diferiu estatisticamente da dose $80 \mathrm{~N}$.

O nitrogênio é o nutriente requerido em maior quantidade pelo milho. Alguns autores comentam que a requisição desse nutriente e tão alta que mesmo fazendo adubações de base e cobertura, muitas vezes essa necessidade não é totalmente atendida (AMADO et al., 2002). O crescimento da planta e o índice de produtividade estão diretamente ligados à disponibilidade desse nutriente para a planta, sendo que a resposta às doses de $\mathrm{N}$ aplicadas varia de acordo com $\mathrm{O}$ potencial produtivo de cada material. Isso pôde ser observado na Tabela 5, onde as diferentes doses de $\mathrm{N}$ proporcionaram diferentes resultados para as alturas de planta e para a produção de grãos.

Através da análise de trilha, verificou-se que AP4 foi o componente de rendimento que apresentou a maior correlação total com a produtividade $(0,462)$, quando utilizado a dose $20 \mathrm{~N}$, superando os demais componentes. O segundo componente com maior coeficiente foi AP4 $(0,444)$ com utilização da dose $140 \mathrm{~N}$ (Tabela 6). Isso demonstra a importância desse componente sobre a produtividade de grãos. O terceiro componente com maior coeficiente foi AP1 $(0,431)$ para dose 140 N. Pôde se observar que apenas esses três componentes obtiveram uma correlação positiva e significativa com a produção de grãos. 
Tabela 6. Efeitos diretos e indiretos da análise de trilha da altura de plantas sobre a produção de grãos (PG em g.planta-1) de 12 genótipos de milho avaliados sob três doses de nitrogênio na safra 2012/2013, Gurupi- TO, Brasil.

Table 6. Direct and indirect effects of plant height path analysis about grain production ( $P G$ g planta in ${ }^{-1}$ ) in the 12 maize genotypes evaluated under three levels of nitrogen in the 2012/2013 harvest, Gurupi- TO, Brazil.

\begin{tabular}{|c|c|c|c|}
\hline \multirow{2}{*}{ Características } & \multicolumn{3}{|c|}{ Nitrogênio } \\
\hline & 20 & 80 & 140 \\
\hline \multicolumn{4}{|l|}{ AP1 } \\
\hline Efeito direto sobre PG & 0,866 & 0,852 & 0,795 \\
\hline Efeito indireto via AP2 & $-1,292$ & $-0,599$ & $-0,045$ \\
\hline Efeito indireto via AP3 & 0,012 & $-0,061$ & $-0,469$ \\
\hline Efeito indireto via AP4 & 0,482 & 0,123 & 0,149 \\
\hline Total & 0,068 & 0,315 & $0,431 * *$ \\
\hline \multicolumn{4}{|l|}{ AP2 } \\
\hline Efeito direto sobre PG & $-1,481$ & $-0,753$ & $-0,056$ \\
\hline Efeito indireto via AP1 & 0,755 & 0,678 & 0,640 \\
\hline Efeito indireto via AP3 & 0,013 & $-0,060$ & $-0,553$ \\
\hline Efeito indireto via AP4 & 0,398 & 0,122 & 0,142 \\
\hline Total & $-0,314$ & $-0,014$ & 0,173 \\
\hline \multicolumn{4}{|l|}{ AP3 } \\
\hline Efeito direto sobre PG & 0,015 & $-0,082$ & $-0,692$ \\
\hline Efeito indireto via AP1 & 0,683 & 0,632 & 0,539 \\
\hline Efeito indireto via AP2 & $-1,306$ & $-0,555$ & $-0,045$ \\
\hline Efeito indireto via AP4 & 0,470 & 0,150 & 0,177 \\
\hline Total & $-0,138$ & 0,145 & $-0,021$ \\
\hline \multicolumn{4}{|l|}{ AP4 } \\
\hline Efeito direto sobre PG & 0,698 & 0,264 & 0,468 \\
\hline Efeito indireto via AP1 & 0,598 & 0,397 & 0,254 \\
\hline Efeito indireto via AP2 & $-0,844$ & $-0,348$ & $-0,017$ \\
\hline Efeito indireto via AP3 & 0,010 & $-0,047$ & $-0,261$ \\
\hline Total & $0,462 * *$ & 0,267 & $0,444 * *$ \\
\hline Coeficiente de determinação & 0,844 & 0,338 & 0,555 \\
\hline Efeito da variável residual & 0,395 & 0,814 & 0,667 \\
\hline
\end{tabular}

$*, * *$ Significativo à $5 \%$ e $1 \%$ respectivamente pelo teste $\mathrm{t}$.

*, ** Significant at the $5 \%$ and $1 \%$ respectively by $t$ test.

Na AP1 os valores de correlação para o efeito direto na produção de grãos foram alto e positivo para todas as três doses de N (Tabela 6). No entanto, se observou efeitos indiretos de sinal negativo via AP2 quando utilizado as três doses, e via AP3 quando se utilizou as doses $80 \mathrm{~N}$ e $140 \mathrm{~N}$, fazendo com que os coeficientes de correlação total tornassem baixos, com exceção para a dose $140 \mathrm{~N}$, que sofreu efeito indireto positivo e alto via AP4, elevando seu coeficiente de correlação total para $(0,431)$.

$\mathrm{Na}$ AP2 o efeito direto na produção de grãos foi negativo para todas as doses de $\mathrm{N}$ (Tabela 6 ). Consequentemente os valores da correlação total entre essas características foram baixos e negativos, exceto com a utilização da dose $140 \mathrm{~N}$ que apesar de baixa foi positiva $(0,173)$. O que influenciou de forma indireta e negativa todas as demais características. Isso demonstra que não existiu importância desse componente sobre a produtividade de grãos, e que seu efeito sobre ela é negativo.

Na AP3 o efeito direto positivo na produção de grãos foi observado com a dose $80 \mathrm{~N}$, e negativo com as demais doses de $N$ (Tabela 6) que juntamente com o efeito negativo e indireto via AP2, proporcionaram um coeficiente total baixo com o uso de todas as doses e negativo para as doses $20 \mathrm{~N}$ e $140 \mathrm{~N}$, enquanto na AP4 o efeito direto na produção de grãos foi maior e positivo, mesmo sofrendo efeito indireto (+) via AP1, e efeito indireto (-) via AP2 para todas as doses de N (Tabela 6). Isso 
comprova uma associação positivas entre plantas mais altas (estágio VT-R1) e maior produção de grãos (FARIA et al., 2014), podendo ser explicado por uma maior área fotossintética, absorvendo maior quantidade de luz e consequentemente obtendo maior produção de fotoassimilados (ANDRADE et al., 2007).

Para as características de taxa de crescimento (TX1, TX2 e TX3), de acordo com a análise de trilha o maior coeficiente de correlação total apresentado foi para TX3 $(0,661)$ quando utilizado a dose $20 \mathrm{~N}$, e em seguida TX3 $(0,393)$ com a dose $140 \mathrm{~N}$ (Tabela 7). Quanto a característica TX1, foi possível notar que o seu efeito direto sobre a produção de grãos apesar de positivo para as doses $20 \mathrm{~N}$ e $140 \mathrm{~N}$ são valores muito baixo, contribuindo muito pouco diretamente (Tabela 7).

Observando o coeficiente de correlação total, é clara a interferência negativa indireta da TX3 sobre a produção de grãos, fazendo com que esse coeficiente fique alto, porém negativo. Isso demonstra que essa característica não foi desejável para o incremento da produção de grãos.

Para a característica TX2 o efeito direto na produção de grãos foi observado positivamente quando se utilizou as doses $20 \mathrm{~N}$ e $80 \mathrm{~N}$ e negativamente com a dose $140 \mathrm{~N}$, sendo esses valores baixos, exceto para dose $20 \mathrm{~N}(0,526)$. Mas devido ao efeito indireto de TX3 sobre a produção de grãos, o valor do coeficiente total foi reduzido enquanto para a TX3 observou um efeito direto positivo com a produção de grãos, com destaque para a utilização da dose $20 \mathrm{~N}$ cujo valor $(0,864)$ foi o maior encontrado, mostrando que entre as três características avaliadas, essa foi a mais eficiente e a que mais contribuiu para a produção de grãos (Tabela 7).

Tabela 7. Efeitos diretos e indiretos da análise de trilha da taxa de crescimento sobre a produção de grãos (PG em g.planta ${ }^{-1}$ ) de 12 genótipos de milho avaliados sob três doses de nitrogênio na safra 2012/2013, Gurupi- TO.

Table 7. Direct and indirect effects of growth rate path analysis about grain production ( $P G$ g.planta in-1) in the 12 maize genotypes evaluated under three levels of nitrogen in the 2012/2013 harvest, Gurupi-TO.

\begin{tabular}{|c|c|c|c|}
\hline \multirow{2}{*}{ Características } & \multicolumn{3}{|c|}{ Nitrogênio } \\
\hline & 20 & 80 & 140 \\
\hline \multicolumn{4}{|l|}{ TX1 } \\
\hline Efeito direto sobre PG & 0,084 & $-0,072$ & 0,077 \\
\hline Efeito indireto via TX2 & 0,005 & $-0,037$ & $-0,001$ \\
\hline Efeito indireto via TX3 & $-0,575$ & $-0,079$ & $-0,179$ \\
\hline Total & $-0,486 * *$ & $-0,188$ & $-0,103$ \\
\hline \multicolumn{4}{|l|}{ TX2 } \\
\hline Efeito direto sobre PG & 0,526 & 0,324 & $-0,090$ \\
\hline Efeito indireto via TX1 & 0,001 & 0,008 & 0,001 \\
\hline Efeito indireto via TX3 & $-0,242$ & $-0,103$ & $-0,162$ \\
\hline Total & 0,285 & 0,229 & $-0,252$ \\
\hline \multicolumn{4}{|l|}{ TX3 } \\
\hline Efeito direto sobre PG & 0,864 & 0,199 & 0,391 \\
\hline Efeito indireto via TX1 & $-0,056$ & 0,029 & $-0,035$ \\
\hline Efeito indireto via TX2 & $-0,147$ & $-0,167$ & 0,038 \\
\hline Total & $0,661 * *$ & 0,061 & $0,393^{*}$ \\
\hline Coeficiente de determinação & 0,680 & 0,100 & 0,168 \\
\hline Efeito da variável residual & 0,566 & 0,949 & 0,912 \\
\hline
\end{tabular}

Mesmo as características TX1 e TX2 tendo efeito indireto negativo sobre a produção de grãos, o coeficiente total para essa característica (TX3) se manteve alto, podendo essa ser a característica a mais importante para incrementos de produção de grãos entres as demais. Fatores que determinam o número de grãos na espiga nesses estágios (V6-V10), tem se mostrado mais importante que uma maior 
taxa de crescimento durante esse período crítico de determinação do potencial produtivo da planta. Indicando o fato de novos materiais de milho serem mais produtivos (ECHARTE et al., 2000). Isso pode explicar o motivo pelo qual as TX1 e TX2 não apresentaram bons resultados de incremento para a produção de grãos, ou seja, que nesses estádios a planta pode estar utilizando o $\mathrm{N}$ absorvido para determinação de outras características (Número de grãos por fileira, número de fileiras na espiga, diâmetro e comprimento da espiga) diretamente importantes para a produção de grãos.

É possível observar também que não existiu uma associação positiva entres as três características, pois quando uma atua direta e positivamente sobre a produção de grãos as demais características atuam com efeito indireto negativo. Isso leva a concluir que elas poderiam ser utilizadas separadamente.

Valores maiores do coeficiente de determinação, em relação ao efeito da variável residual demonstram que as características analisadas conseguem explicar a variável dependente, segundo Coimbra et al., (1999; 2004). Esse fato pode ser observado somente na dose $20 \mathrm{~N}$, para as características altura de planta e taxa de

\section{REFERÊNCIAS}

ALMEIDA, M. L.; SANGOI, L.; NAVA, I. C.; GALIO, J.; TRENTIN, P. S.; RAMPAZZO, C. Crescimento inicial de milho e sua relação com o rendimento de grãos. Ciência Rural, Santa Maria, v.33, n.2, p.189-194, 2003.

AMADO, T. J. C.; MIELNICZUK, J.; AITA, C. Recomendação de adubação nitrogenada para o milho no RS e SC adaptada ao uso de culturas de cobertura do solo, sob sistema plantio direto. Revista Brasileira de Ciência do Solo, v. 26, n. 1, 2002, p. 241-248.

ANDRADE, C. L. T.; AMARAL, T. A.; GOMIDE, R. L.; ALBUQUERQUE, P. E. P.; HEINEMANN, A. B.; MENDES, A. P.; ALVES, F. F.; ARAUJO, S. G. Área Foliar e Produtividade de Grãos de Cultivares de Milho, Submetidas à Déficit Hídrico, em Sete lagoas, MG. Embrapa. Sete Lagoas, MG. 2007.

ANDRADE, F.H.; UHART, S.A.; FRUGONE, M. Intercepted radiation at flowering and kernel number in maize: shade versus plant density effects. Crop Science, Madison, v.33, p.482- 485, 1993a.

ANDRADE, F. H.; UHART, S. A.; CIRILO, A. G. Temperature affects radiation use efficiency in maize. Field Crops Research, Amsterdan, v.32, p.17-25, 1993b. crescimento, onde os valores do coeficiente de determinação encontrados foram: 0,844 e 0,680 respectivamente, mostrando que a altura de planta conseguiu explicar com maior eficiência a variável dependente (PG).

\section{CONCLUSÕES}

Os genótipos P2, AL Piratininga, Órion e Bras 3010 foram os que apresentaram os melhores resultados tanto para as avalições de altura de planta, taxa de crescimento e os maiores valores de produção de grãos.

O nitrogênio influenciou de forma significativa as características altura de planta e produção de grãos, com maior eficiência observada para a dose $80 \mathrm{~N}$.

Para seleção indireta da variável dependente (PG), o ambiente que se mostrou mais eficiente foi $20 \mathrm{~N}$.

\section{AGRADECIMENTOS}

Ao CNPq pelo apoio e financiamento do trabalho realizado.

À Universidade Federal do Tocantins pelo acompanhamento e apoio durante o desenvolvimento de toda a pesquisa.
ARAUS, J. L.; ELAZAB, A.; VERGARA, O.; SERRET, M. D.; ZAMAN-ALLAH, M.; CAIRNS, J. E. Advances in plant physiology and new Technologies for maize and sorghum phenotyping under water stress. In: Congresso Nacional de Milho e Sorgo. Eficiência Nas cadeias produtivas e o abastecimento global. Anais... Salvador-BA. ABMS, Agosto de 2014. p.29-36.

CIB, Conselho de Informações sobre Biotecnologia. 2006. Guia do milho: tecnologia do campo à mesa. Disponível em:

<http://www.cib.org.br/pdf/guia_do milho_CIB.pdf $>$.

CHARNET, R.; BONVINO, H.; CHARNET, E. M. R.; FREIRE, C. A. L. Análise de modelos de regressão linear com aplicações. Campinas: Unicamp, 2008.

COIMBRA, J. L. M.; GUIDOLIN, A. F.; CARVALHO, F. I. F.; COIMBRA, S. M. M.; MARCHIORO, V. S. Análise de trilha i: análise do rendimento de grãos e seus componentes. Ciência Rural, Santa Maria, v. 29, n. 2, p. 213-218, 1999.

COIMBRA, J. L. M.; GUIDOLIN, A. F.; ALMEIDA, M. L.; SANGOI, L.; ENDER, M.; JÚNIOR, A. M. Análise de trilha dos componentes do rendimento de grãos em genótipos de canola. Ciência Rural, Santa Maria, v.34, n.5, p.14211428, 2004. 
CONAB (Companhia Nacional De Abastecimento), Terceiro Levantamento da safra 2013/2014. Brasília: Ministério da Agricultura, Pecuária e Abastecimento. p. 1-72, dez. 2013. Disponível em: <http://www.conab.gov.br/OlalaCMS/uploads/arquivos $\measuredangle 13 \quad 12 \quad 10160656$ boletim portugues dezembro 2 013.pdf>. Acesso em: 12 Set 2014.

CRUZ, C. D.; REGAZZI, A. J. Modelos biométricos aplicados ao melhoramento genético, Ed. 2, Viçosa: UFV. 1997. 390p.

CRUZ, C. D. Programa GENES - Versão Windows Aplicativo Computacional em Genética e Estatística. UFV:Viçosa, MG, 648p. 2001.

DUARTE, J. B.; VENCOVSKY, R. Interação genótipos $\mathbf{x}$ ambientes: uma introdução à análise AMMI. Ribeirão Preto: Sociedade Brasileira de Genética, 1999. 60p.

ECHARTE, L.; LUQUE, S.; ANDRADE, F. H.; SADRAS, V. O.; CIRILO, A.; OTEGUI, M. E.; VEJA, C. R. C. Response of maize kernel number to plant density in Argentinean hybrids released between 1965 and 1993. Field Crops Research, Amsterdan. v. 68, p. 1-8, 2000.

FANCELLI, A. L.; DOURADO-NETO, D. Produção de Milho. Ed. Agropecuária Guaíba. 360 p., 2000.

FARIA, L. A.; AFFERRI, F. S. Avaliação da adaptabilidade e estabilidade de genótipos de milho na região centro-sul no Estado do Tocantins na safra 2013/2014. Anais... 10 Congresso de Iniciação Científica - Universidade Federal do Tocantins. Palmas-TO, 2014.

FERREIRA, D. F. Programa SISVAR: sistema de análise de variância: versão 4,6 (Build 6,0). Lavras: DEX/UFLA, 2003.

GONÇALVES, M. C.; CORREA, A. M.; DESTRO, D.; Correlations and path analysis of common bean grain yield and its primary components. Crop Breeding and Applied Biotechnology, Londrina, v.3, n.3, p.217-222, 2003.

IBGE, Instituto Brasileiro de Geografia e Estatística. Levantamento sistemático da produção agrícola. 2011. Disponível em: <http://www.ibge.gov.br/home/estatistica/indicadores/ agropecuaria/Ispa/Ispa_201102.pdf>. Acesso em: 18 Ago 2014.

IBGE, Instituto Brasileiro de Geografia e Estatística. Levantamento sistemático da produção agrícola. 2013. Disponível em: <http://www.ibge.gov.br/home/estatistica/indicadores/ agropecuaria/Ispa/Ispa 201304.pdf>. Aceso em: 18 Ago 2014.

INMET, Instituto Nacional de Meteorologia. Boletim meteorológico 2013. <http://www.inmet.gov.br/portal/index.php?r=home/p age\&page=rede estacoes auto graf $>$. Aceso em: 18 Set 2014.

KUREK, A. J.; CARVALHO, F. I. F.; ASSMANN, I.C.; et al. Análise de trilha como critério de seleção indireta para rendimento de grãos em feijão. Revista Brasileira de Agrociência, Pelotas, v.7, n.1, p.29-32, 2001.

MAGALHÃES, P. C.; JONES, R. Aumento de fotoassimilados na taxa de crescimento e peso final dos grãos de milho. Pesquisa agropecuária brasileira, Brasília, p.1747-1754, 1990.

MAGALHÃES, P. C.; DURÃES, F. O. M.; CARNEIRO, N. P.; PAIVA, E. Fisiologia da planta de milho. Sete Lagoas: EMBRAPA-CNPMS, 2002. 23 p. (EMBRAPA-CNPMS. Circular Técnica, 22).

NOGUEIRA, P. A. G.; ZOZ, T.; NUNES. J. G. S.; FILHO, P. R. R.; VENTURINI, G. C. Correlação e análise de trilha de produtividade de grãos e seus componentes e caracteres de planta em milho. Anais... Congresso de Iniciação Científica das Faculdades Integradas de OurinhosFIO/FEMM. 2013.

OTEGUI, M. E.; BONHOMME, R. Grain yield components in maize. I. Ear growth and kernel set. Field Crops Research. Amsterdan, v.56, p.247-256, 1998.

PAVÃO, A. R.; FERREIRA FILHO, J. B. D. S.; Impactos econômicos da introdução do milho Bt11 no Brasil: uma abordagem de equilíbrio geral inter-regional. Revista de Economia e Sociologia Rural, v.49, n.1, p.81-108, 2011.

PAZIANI, S. F.; DUARTE, A. P.; NUSSIO, L. G.; GALLO, P. B.; BITTAR, C. M.; ZOPOLLATTO, M.; RECO, P. C. Características agronômicas e bromatológicas de híbridos de milho para produção de silagem. Revista Brasileira de Zootecnia. v.38, n.3, p.411-417, 2009.

RAMALHO, M. A. P.; SANTOS, J. B.; ZIMMERMANN, M. J. de $O$. Genética quantitativa em plantas autógamas: aplicação ao melhoramento do feijoeiro. Goiânia: UFG, 1993. $271 p$

SINCLAIR, T. R. Historical changes in harvest index and crop nitrogen accumulation. Crop Science, v.38, n.3, p.638-643, 1998.

SOARES, M. O.; MIRANDA, G. V.; GUIMARÃES, L. J. M.; MARRIEL, I. E.; GUIMARÃES, C. T. Parâmetros genéticos de uma população de milho em níveis contrastantes de nitrogênio. Revista Ciência Agronômica, v.42, n.1, p.168174, 2011.

SZELÉS, A. The Indication of Nitrogen deficiency In Maize Growing Using Spad-502 Chlorophyll Meter. Cereal Research Communications, v.35, n.02, p.1149-1152, 2007. 
TOLLENAAR, M. Physiological basis of genetic improvement of maize hybrids in Ontario from 1959 to 1988. Crop Science, Madison, v.31, n.1, p.119-124, 1991.

TOLLENAAR, M.; WU, J. Yield improvement in temperate maize is attributable to greater stress tolerance. Crop Science, v.39, n.6, p.1597-1604, 1999.
WRIGHT, S. Correlation and causation. Journal of Agricultural Research, Washington, DC, v.20, n.7, p.557585, 1921. 